\title{
Role of Allergen Source-Derived Proteases in Sensitization via Airway Epithelial Cells
}

\author{
Yasuhiro Matsumura \\ Department of Internal Medicine, Akishima Hospital, 1260 Nakagami-Cho, Akishima-Shi, Tokyo 196-0022, Japan \\ Correspondence should be addressed to Yasuhiro Matsumura, y-matsumura@aki-hp.jp
}

Received 14 July 2011; Revised 14 September 2011; Accepted 4 October 2011

Academic Editor: Peter Borger

Copyright (C) 2012 Yasuhiro Matsumura. This is an open access article distributed under the Creative Commons Attribution License, which permits unrestricted use, distribution, and reproduction in any medium, provided the original work is properly cited.

Protease activity is a characteristic common to many allergens. Allergen source-derived proteases interact with lung epithelial cells, which are now thought to play vital roles in both innate and adaptive immune responses. Allergen source-derived proteases act on airway epithelial cells to induce disruption of the tight junctions between epithelial cells, activation of protease-activated receptor2 , and the production of thymic stromal lymphopoietin. These facilitate allergen delivery across epithelial layers and enhance allergenicity or directly activate the immune system through a nonallergic mechanism. Furthermore, they cleave regulatory cell surface molecules involved in allergic reactions. Thus, allergen source-derived proteases are a potentially critical factor in the development of allergic sensitization and appear to be strongly associated with heightened allergenicity.

\section{Introduction}

Asthma is regarded as an inflammatory disorder of the airways and has generally been recognized as being driven by T helper 2- (Th2-) skewed Th cell differentiation. Th2-driven cytokines, interleukin (IL)-4 and IL-13, trigger B cells to synthesize IgE, while IL-5 plays a role in eosinophil maturation and survival, and IL-13 regulates airway hyperresponsiveness and mucus hyperplasia.

Epithelial cells clearly play important roles in the initiation of Th2 cell responses to allergens. The epithelial cell layer also acts as a molecular sieve that excludes invaders and plays an important role in homeostasis. Barrier function disorder due to filaggrin (FLG) mutations is critical in the pathogenesis of atopic dermatitis [1]. Although FLG is not expressed in the lower airway respiratory epithelium [2], barrier function of the airway epithelium is impaired in asthma, showing shared common underlying pathogenic mechanisms.

Taking these findings together, asthma can be viewed as a disease of both excessive activation and impairment of airway epithelial barrier function [3-5].

Sources of allergens, such as pollen, house dust mites (HDMs), cockroaches, and fungi, may produce or contain proteases and thereby activate and disrupt the epithelial barrier, causing greater sensitization.

This paper focuses on the importance of allergen sourcederived proteases as a factor contributing to primary sensitization to allergens and to exacerbation of allergic disorders secondary to impaired epithelial barrier function.

\section{Allergen Source-Derived Proteases}

Environmental exposure to allergens is an important determinant of the prevalence of asthma. Allergen source-derived proteases act not only as allergens, but also as promoters of allergenicity.

2.1. Pollens. Pollen allergens have protease activity. The pollens of Japanese cedar (Cryptomeria japonica), Japanese cypress (Chamaecyparis obtusa), and Rocky Mountain juniper (Juniperus scopulorum) contain serine protease activity [6]. An aspartic protease was also recently identified in Japanese cedar pollen allergen [7]. In grass, two serine proteases from short ragweed (Ambrosia artemisiifolia) pollen have been purified and characterized $[8,9]$. Kentucky blue grass (Poa pratensis), rye grass (Lolium perenne), and Bermuda grass (Cynodon dactylon), pollen have also been 
characterized. These pollens exhibited peptidase activity, which appeared to be from serine proteases, but cystein protease activity was also detected in Kentucky and rye grass pollen [10]. Grass pollen major group 1 allergens are reported to be cysteine proteases $[11,12]$. The pollens of white birch (Betula alba) and short ragweed contain not only serine but also cysteine protease activity $[6,13]$.

2.2. HDMs. HDMs produce cysteine and serine proteases. Dermatophagoides pteronyssinus 1 (Der p 1) and Der p 3 [14] are cysteine proteases. Der p 6 and Der p 9 are serine proteases [15-17]. Interestingly, Der p 2, which lacks apparent protease activity, is a structural mimic of MD2, a component of the Toll-like receptor-4 (TLR-4) complex, and can reconstitute a TLR4 signaling complex [18], independently of protease effects.

2.3. Cockroaches. American cockroach (Periplaneta americana) and German cockroach (Blattella germanica) allergen extracts have complex proteolytic activities [19-21]. An approximately $28 \mathrm{kDa}$ trypsin-like serine protease (Per a 10) was purified and characterized from the whole body extract of American cockroaches [22, 23]. Bla g 2, a potent allergen from German cockroaches, has been identified as an aspartic protease $[24,25]$. German cockroach extract is rich in proteases and exerts direct proinflammatory effects on airway epithelial cells. These proinflammatory effects are abolished by serine inhibitors [26], suggesting the involvement of a serine protease. However, the presence and activities of proteases in cockroach extracts, especially those targeting aspartate, cysteine, and serine, remain controversial [27].

2.4. Fungi. A large number of mold species are known to harbor proteases. Serine proteases of airborne fungi have been identified in Penicillium, Aspergillus, Rhodotorula, Curvularia, and Cladosporium species [28-31]. Cross-reactivity has been reported among fungal species [32-35]. The active protease of Epicoccum purpurascens, Epi p 1, which is a potent fungal allergen source inducing respiratory allergic disorders worldwide, also plays an important role in driving allergic responses in the airways of murine models [36].

Recent research has focused on the role of exogenous allergen proteases in allergic disorders. Enzymatic activities have been proposed to facilitate sensitization to various allergens [37-39].

\section{Disruption of Epithelial-Cell Barrier}

In the clinical setting of asthma, there is evidence that the barrier function of the airway epithelium is impaired [4043]. The airway epithelium serves as a barrier via the formation of tight junctions (TJs) which seal off the paracellular space. TJs also have gate functions that regulate the passage of ions and macromolecules through the paracellular pathway. TJs are comprised of a series of interacting proteins and receptors including zonula occludens ( $\mathrm{ZOs}$ ) proteins $\mathrm{ZO}$ $1-3$, occludin, claudins $1-5$, and transmembrane adhesion proteins $(\beta$-catenin, E-cadherin, and junctional adhesion molecule-1). These proteins and receptors appear to interact in a homophilic manner. ZO-1, -2 , and -3 bind to the cytoplasmic tail of occludin and link the TJ to the actin cytoskeleton. Occludin appears to copolymerize to form claudin-based TJ strands. Claudins adhere to each other in a homotypic as well as a heterotypic manner, determining the barrier properties of cell-cell contact existing between two neighboring cells, and regulate paracellular permeability. Regulatory molecules, including tyrosine kinases, proteases, and GTPases, colocalize near the tight junction. Coordinated functions between the transmembrane components and cytoplasmic molecules, along with the cytoskeleton and regulatory molecules, play a crucial role in not only barrier function but also communication between adjacent cells as well as in the regulation of intercellular transport $[44,45]$.

Initiation of sensitization to allergens in the airway is preceded by their uptake and processing by a subpopulation of mucosal dendritic cells (DCs), followed by presentation of specific peptide epitopes to naïve $\mathrm{T}$ cells in association with major histocompatibility (MHC) class II. Mucosal DCs are positioned within the epithelium. DCs extend their processes between epithelial cells directly into the airway lumen, as a periscope function that allows continuous immune surveillance of the airway luminal surface. DCs form TJs with epithelial cells through their expression of adhesion molecules and via E-cadherin homotypic interactions [46, 47].

DCs act as immune sentinels by alerting $\mathrm{T}$ cells to the presence of antigens after delivery and presentation to draining lymph nodes. In mice, antigen administered into the lungs is rapidly, that is, in as little as 12 hours, transported to thoracic lymph nodes $[48,49]$. The path taken by inhaled antigens from the airways to sampling by DC subsets has yet to be characterized in detail. Antigen sampling functions may also differ between DCs located in the alveolar wall and mucosal DCs that line the conducting airways $[47,50-52]$.

Although the sampling function of airway DCs ensures that any inhaled protein will be recognized and presented to $\mathrm{T}$ cells, allergen source-derived proteases compromise epithelial barrier function by degrading TJ proteins, thus facilitating allergen delivery across epithelial layers.

Proteases released by major allergenic pollens have been shown to injure airway epithelial cells in vitro [53]. Proteolytic enzymes contained in pollens of giant ragweed (Ambrosia trifida), white birch, Kentucky blue grass, and Easter lily (Lilium longiflorum) facilitate allergen delivery across epithelia by degrading occludin, resulting in disruption of epithelial TJs. This effect was blocked by inhibitors of serine and cysteine proteases in Madin-Darby canine kidney (MDCK) and Calu-3 cells [54].

Der p 1 increased epithelial permeability by disrupting TJs [55]. Immunoblotting demonstrated that the disruption of TJ morphology by Der $\mathrm{p} 1$ was associated with cleavage of ZO-1 and occludin in MDCK and 16HBE14o-human bronchial epithelial cell lines [56]. Putative Der p 1 cleavage sites were found in peptides from an extracellular domain of occludin and in the TJ adhesion protein claudin-1. Extracellular cleavage of TJs initiates intracellular processing of junctional constituents. Der p 1 is also envisaged to 
operate indirectly on TJs by activating a cell surface zymogen, which then proceeds to cleave TJs [57]. ZO-1 is intracellular and is therefore unlikely to be directly degraded by Der $\mathrm{p} 1$, and its breakdown is presumed to be a consequence of $\mathrm{TJ}$ disassembly [57].

Der $\mathrm{p} 1$ and Dermatophagoides farinae 1 (Der f 1) can inactivate lung surfactant proteins (SP)-A and -D [58], which are predominantly synthesized and secreted in the lung by alveolar type II cells and Clara cells. SP-A and-D are known to play not only significant roles in innate immune defense such as bacterial aggregation and modulation of leukocyte function, but also are implicated in the allergic response [59, 60].

Allergens, derived from cockroach extracts, are reported to increase the permeability of bronchial airway epithelial cells indirectly through the induction of vascular endothelial growth factor [61] and thereby gain access to intraepithelial DCs.

Aspergillus fumigatus proteinase directly induces human epithelial cell detachment [62]. Pen ch 13, a major allergen of Penicillium chrysogenum, is a serine protease. Its enzymatic activity damages the epithelial barrier by cleaving the TJ protein occludin at Gln202 and Gln211, amino acids within the second extracellular domain of the protein on 16HBE14ocells [63], followed by the induction of proinflammatory responses in epithelial cells.

Epithelial injury and aberrant repair are involved in triggering asthma. Interestingly, Pen ch 13 decreases cell surface expression of CD44 in 16HBE14o-cells and primary bronchial epithelial cells [64], which has been suggested to contribute to repair of epithelial damage [65]. CD44 is a transmembrane adhesion molecule and the major receptor for hyaluronan, a major extracellular matrix component. CD44 is important for the removal of extracellular matrix from sites of tissue injury, and impaired clearance of hyaluronan results in persistent inflammation $[66,67]$.

Thus, loss of epithelial barrier function, as a consequence of proteases associated with allergens, facilitates antigen access to DCs. The result is that the adaptive immune response is skewed towards Th2 cells, and the IgE immune response is amplified.

Most results are based on in vitro study. Since the digestion process of proteases needs a suffientcient local concentration and time, dilution in mucus, as well mucociliary clearance of the respiratory tract, may complicate the digestion process of TJs in vivo.

\section{Allergen Source-Derived Proteases Activate Pattern Recognition Receptors (PRRs)}

Pulmonary epithelial cells are now thought to play vital roles in both innate and adaptive immune responses. Epithelial cells can sense and respond to inhaled allergens or proteases via activation of a variety of pattern recognition receptors (PRRs) such as TLR and PAR. These activated receptor signals trigger nuclear factor $\kappa \mathrm{B}(\mathrm{NF}-\kappa \mathrm{B})$ activation, leading to transcriptional activation of several proinflammatory genes including those encoding cytokines and chemokines. Epithelial production of thymic stromal lymphopoietin
(TSLP), granulocyte-macrophage colony stimulating factor (GM-CSF), and IL-33 and IL-25, as well as the production of chemokines, both attract and activate DCs, skewing T-cell production toward to the Th2 subset.

\section{PAR-2}

Protease allergens are reported to elicit non-IgE-mediated airway reactions by triggering innate immunity receptors, such as PARs, to activate epithelial cells, mast cells, and DCs, which in turn leads to further release of mediators [68]. PARs constitute a novel family of seven-transmembrane Gprotein-coupled receptors. To date, four PARs have been identified and cloned. They are widely expressed on cells comprising blood vessels, connective tissue, epithelium, and airways, as well as on leukocytes [69]. PARs are activated by proteolytic cleavage at the amino terminus, allowing interaction between the newly formed "tethered ligand" and the second extracellular loop of the receptor. This interaction confers a cellular signaling property. PARs can also be activated by small peptides that mimic the tethered ligand. Activated PARs coupled to G-signaling cascades increase phospholipase $\mathrm{C}$ level, which in turn raises intracellular calcium $\left(\mathrm{Ca}^{2+}\right)$ level [70-72]. G protein activation also generates a transcriptional response through extracellular signal-regulated and mitogen-activated protein kinases, as well as NF- $\kappa$ B [73-75].

In patients with bronchial asthma, PAR-2 expression is increased on the surface of respiratory epithelial cells [76, 77]. PAR2 agonists induce constriction of human bronchi [78]. Lack of PAR-2 expression is reported to lower inflammatory cell infiltration and reduce airway hyperreactivity in response to allergen challenge in mice [79].

Asthma is associated with increased water and chloride $\left(\mathrm{Cl}^{-}\right)$secretion into the airway lumen due to elevated expression of $\mathrm{Ca}^{2+}$-activated $\mathrm{Cl}^{-}$channels [80-82]. Stimulation of PAR-2 receptors in mouse and human airways inhibited amiloride-sensitive sodium $\left(\mathrm{Na}^{+}\right)$conductance and stimulated luminal $\mathrm{Cl}^{-}$channels and basolateral potassium $\left(\mathrm{K}^{+}\right)$channels, which together may cause accumulation of airway surface fluid [83].

Activation of PAR-2 was, however, shown to reduce airway inflammation in a rabbit model of experimental asthma [84], which supports the concept of PAR-2 being a cytoprotective receptor involved in prostanoid-dependent cytoprotection in the airways. Prostaglandin E (PGE), which inhibits pulmonary infiltration by immune cells and bronchial constriction in allergen-induced asthma, is produced by cultured airway smooth muscle cells $[85,86]$, as well as airway epithelial cells, follicular DCs, fibroblasts, monocytes, and alveolar macrophages [87]. Intranasal administration of PAR-2-AP was shown to inhibit airway eosinophilia and hyperresponsiveness in allergic mice via cyclooxygenase- (COX-) 2-dependent generation of $\mathrm{PGE}_{2}$ [88].

Thus, whether the activation of PAR-2 promotes or opposes the progression of airway inflammatory responses depends on the experimental model and species and is not yet fully understood. This is an area requiring further research. 
PAR-2 is a major candidate for sensing environmental exposure to serine proteases. PAR-2 is involved in antigeninduced asthmatic responses, including increase in IgE production, a heightened methacholine response, upregulated production of IL-6, IL-8, GM-CSF, and eotaxin, increased matrix metalloproteinase-9 (MMP-9) release, and relaxation of bronchi $[89,90]$. Interestingly, MMP-9, which plays an important role in remodeling of the airways in disease, is hypothesized to exert its effects on the epithelium by cleaving one or more components of cell-cell junctions and triggering anoikis [91].

Increased release of proinflammatory cytokines, such as IL-6 and IL-8, from airway epithelial cells in response to proteases contained HDM $[92,93]$. Der p 3 and Der p 9 may induce a non-allergic inflammatory response in the airways, via release of proinflammatory cytokines from the bronchial epithelium, which is at least partially mediated by PAR-2 [94]. Although release of IL-6 and IL-8, due to the protease activity of Der p 1, can occur via a mechanism independent of $\mathrm{Ca}^{2+}$ mobilization and PAR activation [95, 96], their release from an A549 cell line was reported to be associated with PAR-2 [97].

Fungal proteases, from Aspergillus fumigates, Alternaria alternate, and Cladosporium herbarum, differentially induced morphologic changes, cell desquamation, and the production of various cytokines [98, 99]. The protease activity of Pen ch 13, an allergen from Penicillium chrysogenum, is required for the induction of PGE2, IL-8, transforminggrowth-factor- (TGF-) betal and COX-2 expression in A549 cells, 16HBE14o-cells, and primary cultures of HBEpC [63]. Pen c 13, the main allergen produced by Penicillium citrinum, induces the expression of IL- 8 in human airway epithelial cells by activating either PAR-1 or PAR-2 [100].

Fecal remnants [101] and extracts [102] of German cockroach induced mucosal allergic sensitization and inflammation via PAR-2 in mice. Inflammatory responses of human eosinophils to German and Oriental cockroach (Blatta orientalis) extract antigens are mediated via PAR-2 [27, 103]. Recent data provide evidence implicating the protease activity of cockroaches in cytokine regulation. Allergens of German and American cockroaches induce IL-8 expression in H292 cells [104] and A549 cells [105], respectively, and both are blocked by serine protease inhibitors, suggesting PAR-2 might play a role in cockroach allergen-induced IL-8 secretion from human airway epithelial cells [105]. Proteases in German cockroach extract regulate PAR-2 and extracellular signal-regulated kinase (ERK) to increase NF for IL-6 (NF-IL6) activity (recently known as C/EBP- $\beta$ ), as well as synergistically regulating TNF- $\alpha$-induced IL-8 promoter activity in the human airway epithelium [104, 106-108]. German cockroach fecal remnants contain active serine proteases, which augment TNF- $\alpha$-induced MMP-9 expression via a mechanism that involves PAR-2, ERK, and AP-1 [109].

Interestingly, exposure to inhaled antigens with a PAR2-activating peptide led to allergic sensitization, whereas exposure to $\mathrm{Ag}$ alone induced tolerance in $\mathrm{BALB} / \mathrm{c}$ mice administered ovalbumin (OVA), suggesting PAR-2 activation in the airways at the time of inhaled antigen exposure to be capable of shifting the resulting immune response toward allergic sensitization and the development of asthma. Furthermore, PAR-2-mediated allergic sensitization is reported to be TNF dependent [110].

\section{Thymic Stromal Lymphopoietin}

In addition to serving as a physical barrier, airway epithelial cells are now thought to play essential roles in allergic responses. TSLP [111] is expressed mainly by epithelial cells comprising the barrier surfaces of the lungs. Genetic analyses of atopic populations have demonstrated polymorphisms in TSLP to be associated with asthma and airway hyperresponsiveness, IgE concentration, and eosinophilia [112-116]. Overexpression of TSLP in the lungs can trigger Th2 cell immunity. Mice expressing TSLP in the lungs spontaneously develop an airway inflammatory disorder with characteristics similar to those of human asthma [117].

Studies of endobronchial biopsy specimens and BAL fluid of subjects with severe asthma have shown that asthma is associated with elevated bronchial mucosal expression of TSLP and Th1-attracting (IP-10/CXCL10) and Th2attracting (TARC/CCL17, MDC/CCL22) chemokines [118, 119].

IL-25 and TSLP perform important functions in the initiation of allergic responses [120-122]. TSLP expression is induced in airway epithelial cells by exposure to allergenderived proteases, and PAR-2 is involved in this process. A recent study demonstrated upregulation of IL-25 and TSLP mRNA in pulmonary epithelial cells after protease allergen treatment in vivo and in vitro, and that the induction of IL25 and TSLP occurs via the intracellular ERK and p38 MAP kinase pathways [123]. TSLP induces the innate immune functions of DCs, leading to chemokine-driven recruitment of Th2 cells to the airway, and these cells then produce Th2 type cytokines. TSLP also triggers the maturation of DCs and their migration to mediastinal lymph nodes, again skewing the T-cell distribution in favor of inflammatory Th2 cells producing IL-4, IL-5, IL-13, and TNF- $\alpha$. These processes involve interactions between costimulatory molecules, such as OX40 (CD134) in the membranes of naïve T cells and OX40L (CD134L) in the membranes of DCs $[124,125]$. TSLP was reported to be induced in the airway epithelial cell line BEAS-2B by exposure to Alternaria proteases [126] (see Figure 1).

Basophils are directly activated by protease allergens and produce TSLP. Cysteine protease activity of papain, an occupational allergen homologous to Der $\mathrm{f} 1$ and Der $\mathrm{p} 1$, was reported to initiate Th2 sensitization in vivo in mice via activation of basophils [122].

\section{Allergen Source-Derived Proteases Enhance Sensitization to Other Allergens and Allergen Components}

The tertiary structure of an allergen is involved in IgEbinding activity. The tertiary architecture of the Der $\mathrm{p} 1$ molecule itself is not sufficient to induce major production 


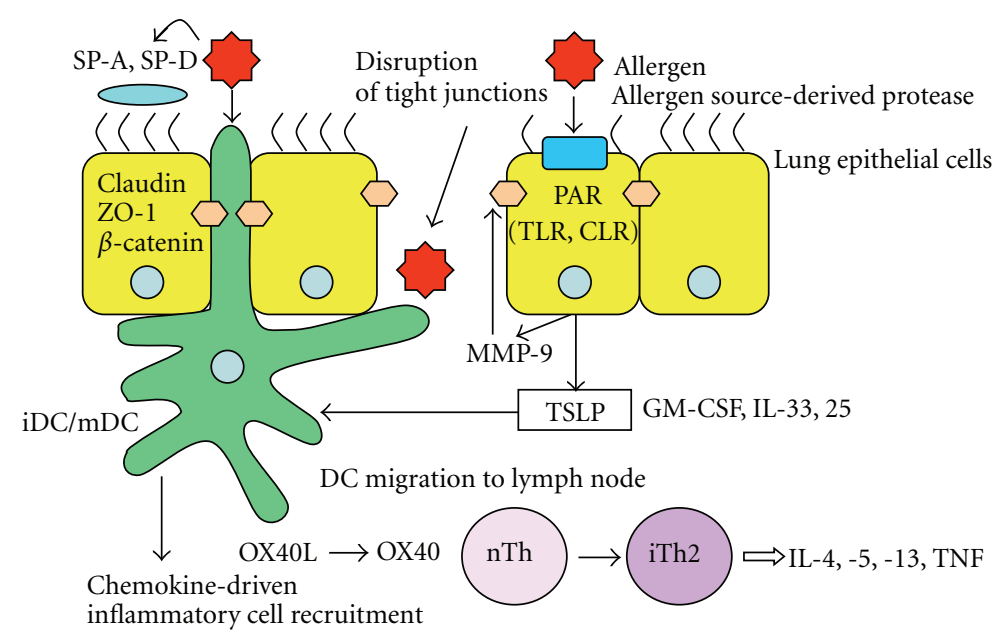

Figure 1: Allergen source-derived proteases compromise epithelial barrier function by degrading TJ proteins, facilitating allergen accessibility to DCs. Enzymatically active allergens can activate PAR to induce TSLP. TSLP induces immediate innate immune functions in DCs, leading to recruitment of inflammatory cells. TSLP triggers the maturation of DCs, so they migrate to mediastinal lymph nodes. Induction of DCs to upregulate OX40L by TSLP promotes Th2 responses. PAR also upregulates production of MMP-9, which degrades tight junction proteins. Thus, impairment of airway epithelial barrier function and activation of epithelial cells are involved in the pathogenesis of inflammation mediated by allergen source-derived proteases.

of both IgE and IgG, but its proteolytic activity is crucial for eliciting positive immune responses in naïve mice [127].

Immunization of mice with proteolytically active Der $\mathrm{p}$ 1 results in significant increases in total IgE and Der $\mathrm{p}$ 1specific IgE synthesis, as compared with animals immunized with Der p 1 irreversibly blocked with E-64, a cysteine protease inhibitor [128]. The proteolytic activity of Der $p 1$ heightens inflammatory cell infiltration into the lungs and systemic IgE production when administered directly into the respiratory tract [129].

Allergens with protease activity are also able to mediate sensitization to nonprotease proteins. Exposure to HDM extract establishes a mucosal environment fostering the development of allergic sensitization to otherwise weak or innocuous antigens, such as OVA, suggesting that whether an airborne allergen will generate allergic airway disease may depend, at least in part, not simply on being exposed to it but rather the setting in which that exposure takes place $[130,131]$.

Active protease contents of fungal extracts can influence the induction and severity of allergic airway disease in mice. Proteolytically active molecules can facilitate the presentation of nonproteolytic allergens to the immune system, thereby augmenting sensitization to allergens. These proteolytic allergens thereby promote Th2 cell sensitization. For a mature response, the participation of components such as enzymes may have a major role, as is suggested by the response reported with crude antigen and recombinant allergens. Alkaline serine proteases are major allergens of Aspergillus species. The alkaline serine protease allergen of $A$. fumigatus (Asp f 13) induces IgE as well as an inflammatory response and has synergistic effects on the Asp f 2-induced immune response in mice $[31,132]$.

\section{Allergen Source-Derived Proteases Cleave Cell Surface Molecules:Roles beyond the Airways}

Allergen source-derived proteases have been recognized as having the ability to cleave key regulatory molecules in allergic reactions involving cell surfaces, and to amplify $\operatorname{IgE}$ responses.

Previously suggested pathogenic roles of exogenous proteases, especially Der p 1, involve cleavage of various endogenous proteins, including removal of low-affinity IgER (CD23) from the surface of human B lymphocytes. This loss of cell surface CD23 from IgE-secreting B cells may promote and amplify IgE immune responses by eliminating an important inhibitory feedback mechanism that would normally limit IgE synthesis. Furthermore, fragments of CD23 released by Der $\mathrm{p} 1$ may directly promote IgE synthesis [133].

Der $\mathrm{p} 1$ cleaves the $\alpha$ subunit of the IL-2 receptor (IL$2 \mathrm{R}$ or $\mathrm{CD} 25)$, which is pivotal for Th1 cell propagation, removing it from the surface of human peripheral blood $\mathrm{T}$ cells. As a result, these cells show markedly diminished proliferation and interferon $\gamma$ secretion in response to a potent stimulus such as anti-CD3 antibody. IL-2R cleavage by Der p 1 is likely to cause impaired growth of cells of the Th1 subset and may, as a consequence, bias the immune response toward Th2 cells $[134,135]$.

Der p 1 also cleaves cell surface DC-SIGN and DCSIGNR, which are closely related C-type lectin transmembrane receptors expressed within compartments of the immune system. These molecules then bind to intracellular adhesion molecule-2 (ICAM-2), expressed on endothelial and $\mathrm{T}$ cells, and ICAM-3, expressed on T cells. Both are 
involved in DC trafficking, DC-T-cell interactions, and skewing of the immune response in favor of Th 1 [136].

Proteolytic activity of Der p 1 results in cleavage of CD40 from the DC surface. This deprives DCs of the ability to receive CD40L-mediated signals from $\mathrm{T}$ cells, which is an important pathway stimulating IL-12 production. This downregulation of IL-12 may enable DCs to directly promote the differentiation of naïve T cells toward the Th2 cytokine profile [137].

\section{Conclusion}

Although genetic aspects of airway epithelium barrier deficiency have yet to be determined, both structural and functional abnormalities of the epithelium underlie the pathogenesis of bronchial asthma. Protease activity in allergens confirms that allergenicity not only results from the reaction to an epitope, which is involved in adaptive immune responses by $\mathrm{T}$ and $\mathrm{B}$ cells, but also from disruption of airway barrier function and activation of innate immune responses through epithelial cells [138-140]. Stimulation of PAR-2 signaling by protease allergens participates in the inflammatory process, and may serve as a link between innate and adaptive immune responses.

Analysis of these allergen proteases, which constitute protease-sensing pathways in airway epithelial cells, is essential for elucidating the pathogenesis of allergic asthma. A full understanding of these processes is anticipated to lead to both treatment and preventive measures against asthma development.

\section{References}

[1] C. N. A. Palmer, A. D. Irvine, A. Terron-Kwiatkowski et al., "Common loss-of-function variants of the epidermal barrier protein filaggrin are a major predisposing factor for atopic dermatitis," Nature Genetics, vol. 38, no. 4, pp. 441-446, 2006.

[2] S. Ying, Q. Meng, C. J. Corrigan, and T. H. Lee, "Lack of filaggrin expression in the human bronchial mucosa," Journal of Allergy and Clinical Immunology, vol. 118, no. 6, pp. 13861388, 2006.

[3] S. T. Holgate, "Epithelium dysfunction in asthma," Journal of Allergy and Clinical Immunology, vol. 120, no. 6, pp. 12331244, 2007.

[4] S. T. Holgate, "The airway epithelium is central to the pathogenesis of asthma," Allergology International, vol. 57, no. 1, pp. 1-10, 2008.

[5] H. Hammad and B. N. Lambrecht, "Dendritic cells and airway epithelial cells at the interface between innate and adaptive immune responses," Allergy, vol. 66, no. 5, pp. 579587, 2011.

[6] H. Gunawan, T. Takai, S. Ikeda, K. Okumura, and H. Ogawa, "Protease activity of allergenic pollen of cedar, cypress, juniper, birch and ragweed," Allergology International, vol. 57, no. 1, pp. 83-91, 2008.

[7] A. R. N. Ibrahim, S. Kawamoto, T. Aki et al., "Molecular cloning and immunochemical characterization of a novel major japanese cedar pollen allergen belonging to the aspartic protease family," International Archives of Allergy and Immunology, vol. 152, no. 3, pp. 207-218, 2010.
[8] D. A. Bagarozzi, R. Pike, J. Potempa, and J. Travist, "Purification and characterization of a novel endopeptidase in ragweed (Ambrosia artemisiifolia) pollen," Journal of Biological Chemistry, vol. 271, no. 42, pp. 26227-26232, 1996.

[9] D. A. Bagarozzi, J. Potempa, and J. Travis, "Purification and characterization of an arginine-specific peptidase from ragweed (Ambrosia artemisiifolia) polen," American Journal of Respiratory Cell and Molecular Biology, vol. 18, no. 3, pp. 363-369, 1998.

[10] M. J. Raftery, R. G. Saldanha, C. L. Geczy, and R. K. Kumar, "Mass spectrometric analysis of electrophoretically separated allergens and proteases in grass pollen diffusates," Respiratory Research, vol. 4, 2003.

[11] K. Grobe, W. M. Becker, M. Schlaak, and A. Petersen, "Grass group I allergens ( $\beta$-expansins) are novel, papain-related proteinases," European Journal of Biochemistry, vol. 263, no. 1, pp. 33-40, 1999.

[12] K. Grobe, M. Pöppelmann, W. M. Becker, and A. Petersen, "Properties of group I allergens from grass pollen and their relation to cathepsin $\mathrm{B}$, a member of the $\mathrm{C} 1$ family of cysteine proteinases," European Journal of Biochemistry, vol. 269, no. 8, pp. 2083-2092, 2002.

[13] H. Gunawan, T. Takai, S. Kamijo et al., "Characterization of proteases, proteins, and eicosanoid-like substances in soluble extracts from allergenic pollen grains," International Archives of Allergy and Immunology, vol. 147, no. 4, pp. 276-288, 2008.

[14] O. Schulz, H. F. Sewell, and F. Shakib, "A sensitive fluorescent assay for measuring the cysteine protease activity of Der $p$ 1, a major allergen from the dust mite Dermatophagoides pteronyssinus," Journal of Clinical Pathology, vol. 51, no. 4, pp. 222-224, 1998.

[15] H. Yasueda, H. Mita, K. Akiyama et al., "Allergens from Dermatophagoides mites with chymotryptic activity," Clinical and Experimental Allergy, vol. 23, no. 5, pp. 384-390, 1993.

[16] B. J. Bennett and W. R. Thomas, "Cloning and sequencing of the group 6 allergen of Dermatophagoides pteronyssinus," Clinical and Experimental Allergy, vol. 26, no. 10, pp. 11501154, 1996.

[17] C. King, R. J. Simpson, R. L. Moritz, G. E. Reed, P. J. Thompson, and G. A. Stewart, "The isolation and characterization of a novel collagenolytic serine protease allergen (Der p 9) from the dust mite Dermatophagoides pteronyssinus," Journal of Allergy and Clinical Immunology, vol. 98, no. 4, pp. 739-747, 1996.

[18] A. Trompette, S. Divanovic, A. Visintin et al., "Allergenicity resulting from functional mimicry of a Toll-like receptor complex protein," Nature, vol. 457, no. 7229, pp. 585-588, 2009.

[19] V. K. Hivrale, N. P. Chougule, P. J. Chhabda, A. P. Giri, and M. S. Kachole, "Unraveling biochemical properties of cockroach (Periplaneta americana) proteinases with a gel Xray film contact print method," Comparative Biochemistry and Physiology B, vol. 141, no. 3, pp. 261-266, 2005.

[20] S. Kondo, H. Helin, M. Shichijo, and K. B. Bacon, "Cockroach allergen extract stimulates protease-activated receptor2 (PAR-2) expressed in mouse lung fibroblast," Inflammation Research, vol. 53, no. 9, pp. 489-496, 2004.

[21] V. T. Sudha, D. Srivastava, N. Arora, S. N. Gaur, and B. P. Singh, "Stability of protease-rich periplaneta americana allergen extract during storage: formulating preservatives to enhance shelf life," Journal of Clinical Immunology, vol. 27, no. 3, pp. 294-301, 2007. 
[22] V. T. Sudha, N. Arora, S. N. Gaur, S. Pasha, and B. P. Singh, "Identification of a serine protease as a major allergen (Per a 10) of periplaneta americana," Allergy, vol. 63, no. 6, pp. 768-776, 2008.

[23] V. T. Sudha, N. Arora, and B. P. Singh, "Serine protease activity of per a 10 augments allergen-induced airway inflammation in a mouse model," European Journal of Clinical Investigation, vol. 39, no. 6, pp. 507-516, 2009.

[24] A. Pomés, M. D. Chapman, L. D. Vailes, T. L. Blundell, and V. Dhanaraj, "Cockroach allergen Bla g 2: structure, function, and implications for allergic sensitization," American Journal of Respiratory and Critical Care Medicine, vol. 165, no. 3, pp. 391-397, 2002.

[25] S. Wünschmann, A. Gustchina, M. D. Chapman, and A. Pomés, "Cockroach allergen Bla g 2: an unusual aspartic proteinase," Journal of Allergy and Clinical Immunology, vol. 116, no. 1, pp. 140-145, 2005.

[26] R. K. Bhat, K. Page, A. Tan, and M. B. Hershenson, "German cockroach extract increases bronchial epithelial cell interleukin-8 expression," Clinical and Experimental Allergy, vol. 33, no. 1, pp. 35-42, 2003.

[27] K. Wada, Y. Matsuwaki, J. Yoon et al., "Inflammatory responses of human eosinophils to cockroach are mediated through protease-dependent pathways," Journal of Allergy and Clinical Immunology, vol. 126, no. 1, pp. 169-172, 2010.

[28] C. J. Schwab, J. D. Cooley, T. Brasel, C. A. Jumper, S. C. Graham, and D. C. Straus, "Characterization of exposure to low levels of viable Penicillium chrysogenum conidia and allergic sensitization induced by a protease allergen extract from viable P. chrysogenum conidia in mice," International Archives of Allergy and Immunology, vol. 130, no. 3, pp. 200208, 2003.

[29] C. J. Schwab, J. D. Cooley, C. J. Jumper, S. C. Graham, and D. C. Straus, "Allergic inflammation induced by a Penicillium chrysogenum conidia-associated allergen extract in a murine model," Allergy, vol. 59, no. 7, pp. 758-765, 2004.

[30] N. Y. Su, C. J. Yu, H. D. Shen, F. M. Pan, and L. P. Chow, "Pen c 1, a novel enzymic allergen protein from penicillium citrinum. Purification, characterization, cloning and expression," European Journal of Biochemistry, vol. 261, no. 1, pp. 115-123, 1999.

[31] H. D. Shen, M. F. Tam, R. B. Tang, and H. Chou, "Aspergillus and penicillium allergens: focus on proteases," Current Allergy and Asthma Reports, vol. 7, no. 5, pp. 351-356, 2007.

[32] H. D. Shen, H. Chou, M. F. Tam, C. Y. Chang, H. Y. Lai, and S. R. Wang, "Molecular and immunological characterization of Pen ch 18, the vacuolar serine protease major allergen of penicillium chrysogenum," Allergy, vol. 58, no. 10, pp. 993 1002, 2003.

[33] H. Chou, M. F. Tam, L. H. Lee et al., "Vacuolar serine protease is a major allergen of Cladosporium cladosporioides," International Archives of Allergy and Immunology, vol. 146, no. 4, pp. 277-286, 2008.

[34] V. Pöll, U. Denk, H. D. Shen et al., "The vacuolar serine protease, a cross-reactive allergen from Cladosporium herbarum," Molecular Immunology, vol. 46, no. 7, pp. 13601373, 2009.

[35] P. Bowyer, M. Fraczek, and D. W. Denning, "Comparative genomics of fungal allergens and epitopes shows widespread distribution of closely related allergen and epitope orthologues," BMC Genomics, vol. 7, article 251, 2006.

[36] N. Kukreja, S. Sridhara, B. P. Singh, and N. Arora, "Effect of proteolytic activity of Epicoccum purpurascens major allergen, Epi p 1 in allergic inflammation," Clinical and Experimental Immunology, vol. 154, no. 2, pp. 162-171, 2008.

[37] C. E. Reed, "Inflammatory effect of environmental proteases on airway mucosa," Current Allergy and Asthma Reports, vol. 7, no. 5, pp. 368-374, 2007.

[38] T. Takai, "Missions of protease allergens in the epithelium," International Archives of Allergy and Immunology, vol. 154, no. 1, pp. 3-5, 2010.

[39] A. Jacquet, "Interactions of airway epithelium with protease allergens in the allergic response," Clinical and Experimental Allergy, vol. 41, no. 3, pp. 305-311, 2011.

[40] J. S. Ilowite, W. D. Bennett, M. S. Sheetz, M. L. Groth, and D. M. Nierman, "Permeability of the bronchial mucosa to 99mTc-DTPA in asthma," American Review of Respiratory Disease, vol. 139, no. 5, pp. 1139-1143, 1989.

[41] D. Knight, "Increased permeability of asthmatic epithelial cells to pollutants. Does this mean that they are intrinsically abnormal?" Clinical and Experimental Allergy, vol. 32, no. 9, pp. 1263-1265, 2002.

[42] D. A. Knight and S. T. Holgate, "The airway epithelium: structural and functional properties in health and disease," Respirology, vol. 8, no. 4, pp. 432-446, 2003.

[43] A. Barbato, G. Turato, S. Baraldo et al., "Epithelial damage and angiogenesis in the airways of children with asthma," American Journal of Respiratory and Critical Care Medicine, vol. 174, no. 9, pp. 975-981, 2006.

[44] W. R. Roche, S. Montefort, J. Baker, and S. T. Holgate, "Cell adhesion molecules and the bronchial epithelium," American Review of Respiratory Disease, vol. 148, no. 6, pp. S79-S82, 1993.

[45] C. Förster, "Tight junctions and the modulation of barrier function in disease," Histochemistry and Cell Biology, vol. 130, no. 1, pp. 55-70, 2008.

[46] F. L. Jahnsen, D. H. Strickland, J. A. Thomas et al., "Accelerated antigen sampling and transport by airway mucosal dendritic cells following inhalation of a bacterial stimulus," Journal of Immunology, vol. 177, no. 9, pp. 5861-5867, 2006.

[47] H. Hammad and B. N. Lambrecht, "Dendritic cells and epithelial cells: linking innate and adaptive immunity in asthma," Nature Reviews Immunology, vol. 8, no. 3, pp. 193204, 2008.

[48] K. Y. Vermaelen, I. Carro-Muino, B. N. Lambrecht, and R. A. Pauwels, "Specific migratory dendritic cells rapidly transport antigen from the airways to the thoracic lymph nodes," Journal of Experimental Medicine, vol. 193, no. 1, pp. 51-60, 2001.

[49] H. J. De Heer, H. Hammad, T. Soullié et al., "Essential role of lung plasmacytoid dendritic cells in preventing asthmatic reactions to harmless inhaled antigen," Journal of Experimental Medicine, vol. 200, no. 1, pp. 89-98, 2004.

[50] M. E. Wikstrom and P. A. Stumbles, "Mouse respiratory tract dendritic cell subsets and the immunological fate of inhaled antigens," Immunology and Cell Biology, vol. 85, no. 3, pp. 182-188, 2007.

[51] A. Cleret, A. Quesnel-Hellmann, A. Vallon-Eberhard et al., "Lung dendritic cells rapidly mediate anthrax spore entry through the pulmonary route," Journal of Immunology, vol. 178, no. 12, pp. 7994-8001, 2007.

[52] B. N. Lambrecht and H. Hammad, "The role of dendritic and epithelial cells as master regulators of allergic airway inflammation," The Lancet, vol. 376, no. 9743, pp. 835-843, 2010 . 
[53] F. Widmer, P. J. Hayes, R. G. Whittaker, and R. K. Kumar, "Substrate preference profiles of proteases released by allergenic pollens," Clinical and Experimental Allergy, vol. 30, no. 4, pp. 571-576, 2000.

[54] S. Runswick, T. Mitchell, P. Davies, C. Robinson, and D. R. Garrod, "Pollen proteolytic enzymes degrade tight junctions," Respirology, vol. 12, no. 6, pp. 834-842, 2007.

[55] C. A. Herbert, C. M. King, P. C. Ring et al., "Augmentation of permeability in the bronchial epithelium by the house dust mite allergen Der p1," American Journal of Respiratory Cell and Molecular Biology, vol. 12, no. 4, pp. 369-378, 1995.

[56] H. Wan, H. L. Winton, C. Soeller et al., "Quantitative structural and biochemical analyses of tight junction dynamics following exposure of epithelial cells to house dust mite allergen Der p 1," Clinical and Experimental Allergy, vol. 30, no. 5, pp. 685-698, 2000.

[57] H. Wan, H. L. Winton, C. Soeller et al., "Der p 1 facilitates transepithelial allergen delivery by disruption of tight junctions," Journal of Clinical Investigation, vol. 104, no. 1, pp. 123-133, 1999.

[58] R. Deb, F. Shakib, K. Reid, and H. Clark, "Major house dust mite allergens Dermatophagoides pteronyssinus 1 and Dermatophagoides farinae 1 degrade and inactivate lung surfactant proteins A and D," Journal of Biological Chemistry, vol. 282, no. 51, pp. 36808-36819, 2007.

[59] J. Y. Wang and K. B. M. Reid, "The immunoregulatory roles of lung surfactant collectins SP-A, and SP-D, in allergeninduced airway inflammation," Immunobiology, vol. 212, no. 4-5, pp. 417-425, 2007.

[60] L. R. Forbes and A. Haczku, "SP-D and regulation of the pulmonary innate immune system in allergic airway changes," Clinical and Experimental Allergy, vol. 40, no. 4, pp. 547-562, 2010.

[61] A. B. Antony, R. S. Tepper, and K. A. Mohammed, "Cockroach extract antigen increases bronchial airway epithelial permeability," Journal of Allergy and Clinical Immunology, vol. 110, no. 4, pp. 589-595, 2002.

[62] B. W. S. Robinson, T. J. Venaille, A. H. W. Mendis, and R. McAleer, "Allergens as proteases: an Aspergillus fumigatus proteinase directly induces human epithelial cell detachment," Journal of Allergy and Clinical Immunology, vol. 86, no. 5, pp. 726-731, 1990.

[63] H. Y. Tai, M. F. Tam, H. Chou et al., "Pen ch 13 allergen induces secretion of mediators and degradation of occludin protein of human lung epithelial cells," Allergy, vol. 61, no. 3, pp. 382-388, 2006.

[64] H. Y. Tai, M. F. Tam, H. Chou, D. W. Perng, and H. D. Shen, "Pen ch 13 major fungal allergen decreases CD44 expression in human bronchial epithelial cells," International Archives of Allergy and Immunology, vol. 153, no. 4, pp. 367-371, 2010.

[65] P. Teder, R. W. Vandivier, D. Jiang et al., "Resolution of lung inflammation by CD44," Science, vol. 296, no. 5565, pp. 155$158,2002$.

[66] D. Jiang, J. Liang, and P. W. Noble, "Hyaluronan in tissue injury and repair," Annual Review of Cell and Developmental Biology, vol. 23, pp. 435-461, 2007.

[67] P. Johnson and B. Ruffell, "CD44 and its role in inflammation and inflammatory diseases," Inflammation and Allergy, vol. 8, no. 3, pp. 208-220, 2009.

[68] H. F. Kauffman, "Innate immune responses to environmental allergens," Clinical Reviews in Allergy and Immunology, vol. 30, no. 2, pp. 129-140, 2006.
[69] T. M. Cocks and J. D. Moffatt, "Protease-activated receptor2 (PAR2) in the airways," Pulmonary Pharmacology and Therapeutics, vol. 14, no. 3, pp. 183-191, 2001.

[70] P. Berger, J. M. Tunon-De-Lara, J. P. Savineau, and R. Marthan, "Selected contribution: tryptase-induced PAR-2mediated $\mathrm{Ca} 2+$ signaling in human airway smooth muscle cells," Journal of Applied Physiology, vol. 91, no. 2, pp. 9951003, 2001.

[71] N. M. Schechter, L. F. Brass, R. M. Lavker, and P. J. Jensen, "Reaction of mast cell proteases tryptase and chymase with protease activated receptors (PARs) on keratinocytes and fibroblasts," Journal of Cellular Physiology, vol. 176, no. 2, pp. 365-373, 1998.

[72] J. J. Ubl, Z. V. Grishina, T. K. Sukhomlin, T. Welte, F. Sedehizade, and G. Reiser, "Human bronchial epithelial cells express PAR-2 with different sensitivity to thermolysin," American Journal of Physiology, vol. 282, no. 6, pp. L1339L1348, 2002.

[73] E. Camerer, H. Kataoka, M. Kahn, K. Lease, and S. R. Coughlin, "Genetic evidence that protease-activated receptors mediate factor Xa signaling in endothelial cells," Journal of Biological Chemistry, vol. 277, no. 18, pp. 16081-16087, 2002.

[74] H. Wang, J. J. Ubl, R. Stricker, and G. Reiser, "Thrombin (PAR-1)-induced proliferation in astrocytes via MAPK involves multiple signaling pathways," American Journal of Physiology, vol. 283, no. 5, pp. C1351-C1364, 2002.

[75] V. Temkin, B. Kantor, V. Weg, M. L. Hartman, and F. LeviSchaffer, "Tryptase activates the mitogen-activated protein kinase/activator protein-1 pathway in human peripheral blood eosinophils, causing cytokine production and release," Journal of Immunology, vol. 169, no. 5, pp. 2662-2669, 2002.

[76] D. A. Knight, S. Lim, A. K. Scaffidi et al., "Proteaseactivated receptors in human airways: upregulation of PAR-2 in respiratory epithelium from patients with asthma," Journal of Allergy and Clinical Immunology, vol. 108, no. 5, pp. 797803, 2001.

[77] N. Roche, R. G. Stirling, S. Lim et al., "Effect of acute and chronic inflammatory stimuli on expression of proteaseactivated receptors 1 and 2 in alveolar macrophages," Journal of Allergy and Clinical Immunology, vol. 111, no. 2, pp. 367373, 2003.

[78] F. Schmidlin, S. Amadesi, R. Vidil et al., "Expression and function of proteinase-activated receptor 2 in human bronchial smooth muscle," American Journal of Respiratory and Critical Care Medicine, vol. 164, no. 7, pp. 1276-1281, 2001.

[79] F. Schmidlin, S. Amadesi, K. Dabbagh et al., "Proteaseactivated receptor 2 mediates eosinophil infiltration and hyperreactivity in allergic inflammation of the airway," Journal of Immunology, vol. 169, no. 9, pp. 5315-5321, 2002.

[80] Y. Zhou, Q. Dong, J. Louahed et al., "Characterization of a calcium-activated chloride channel as a shared target of Th2 cytokine pathways and its potential involvement in asthma," American Journal of Respiratory Cell and Molecular Biology, vol. 25, no. 4, pp. 486-491, 2001.

[81] M. Hoshino, S. Morita, H. Iwashita et al., "Increased expression of the human $\mathrm{Ca} 2+$-activated $\mathrm{Cl}$ - channel 1 (CaCC1) gene in the asthmatic airway," American Journal of Respiratory and Critical Care Medicine, vol. 165, no. 8, pp. 1132-1136, 2002.

[82] M. Toda, M. K. Tulic, R. C. Levitt, and Q. Hamid, "A calciumactivated chloride channel (HCLCA1) is strongly related 
to IL-9 expression and mucus production in bronchial epithelium of patients with asthma," Journal of Allergy and Clinical Immunology, vol. 109, no. 2, pp. 246-250, 2002.

[83] K. Kunzelmann, J. Sun, D. Markovich et al., "Control of ion transport in mammalian airways by protease activated receptors type 2 (PAR-2)," FASEB Journal, vol. 19, no. 8, pp. 969-970, 2005.

[84] B. D’Agostino, F. Roviezzo, R. De Palma et al., "Activation of protease-activated receptor-2 reduces airways inflammation in experimental allergic asthma," Clinical and Experimental Allergy, vol. 37, no. 10, pp. 1436-1443, 2007.

[85] T. M. Cocks, B. Fong, J. M. Chow et al., "A protective role for protease-activated receptors in the airways," Nature, vol. 398, no. 6723, pp. 156-160, 1999.

[86] R. S. Lan, G. A. Stewart, and P. J. Henry, "Modulation of airway smooth muscle tone by protease activated receptor$1,-2,-3$ and -4 in trachea isolated from influenza A virusinfected mice," British Journal of Pharmacology, vol. 129, no. 1, pp. 63-70, 2000.

[87] R. Taha, R. Olivenstein, T. Utsumi et al., "Prostaglandin $\mathrm{H}$ synthase 2 expression in airway cells from patients with asthma and chronic obstructive pulmonary disease," American Journal of Respiratory and Critical Care Medicine, vol. 161, no. 2 I, pp. 636-640, 2000.

[88] B. A. De Campo and P. J. Henry, "Stimulation of proteaseactivated receptor-2 inhibits airway eosinophilia, hyperresponsiveness and bronchoconstriction in a murine model of allergic inflammation," British Journal of Pharmacology, vol. 144, no. 8, pp. 1100-1108, 2005.

[89] C. E. Reed and H. Kita, "The role of protease activation of inflammation in allergic respiratory diseases," Journal of Allergy and Clinical Immunology, vol. 114, no. 5, pp. 9971008, 2004.

[90] C. Ebeling, P. Forsythe, J. Ng, J. R. Gordon, M. Hollenberg, and H. Vliagoftis, "Proteinase-activated receptor 2 activation in the airways enhances antigen-mediated airway inflammation and airway hyperresponsiveness through different pathways," Journal of Allergy and Clinical Immunology, vol. 115, no. 3, pp. 623-630, 2005.

[91] P. D. Vermeer, J. Denker, M. Estin et al., "MMP9 modulates tight junction integrity and cell viability in human airway epithelia," American Journal of Physiology, vol. 296, no. 5, pp. L751-L762, 2009.

[92] C. King, S. Brennan, P. J. Thompson, and G. A. Stewart, "Dust mite proteolytic allergens induce cytokine release from cultured airway epithelium," Journal of Immunology, vol. 161, no. 7, pp. 3645-3651, 1998.

[93] J. F.C. Tomee, R. Van Weissenbruch, J. G. R. De Monchy, and H. F. Kauffman, "Interactions between inhalant allergen extracts and airway epithelial cells: effect on cytokine production and cell detachment," Journal of Allergy and Clinical Immunology, vol. 102, no. 1, pp. 75-85, 1998.

[94] G. Sun, M. A. Stacey, M. Schmidt, L. Mori, and S. Mattoli, "Interaction of mite allergens Der p3 and Der p9 with protease-activated receptor-2 expressed by lung epithelial cells," Journal of Immunology, vol. 167, no. 2, pp. 1014-1021, 2001.

[95] E. Adam, K. K. Hansen, O. F. Astudillo et al., "The house dust mite allergen Der p 1, unlike Der p 3, stimulates the expression of interleukin- 8 in human airway epithelial cells via a proteinase-activated receptor-2-independent mechanism," Journal of Biological Chemistry, vol. 281, no. 11, pp. 69106923, 2006.
[96] H. F. Kauffman, M. Tamm, J. A. B. Timmerman, and P. Borger, "House dust mite major allergens Der $\mathrm{p} 1$ and Der $\mathrm{p}$ 5 activate human airway-derived epithelial cells by proteasedependent and protease-independent mechanisms," Clinical and Molecular Allergy, vol. 4, article 5, 2006.

[97] N. Asokananthan, P. T. Graham, D. J. Stewart et al., "House dust mite allergens induce proinflammatory cytokines from respiratory epithelial cells: the cysteine protease allergen, Der $\mathrm{p} 1$, activates protease-activated receptor (PAR)-2 and inactivates PAR-1," Journal of Immunology, vol. 169, no. 8, pp. 4572-4578, 2002.

[98] H. F. Kauffman, J. F. Christomee, M. A. Van De Riet, A. J. B. Timmerman, and P. Borger, "Protease-dependent activation of epithelial cells by fungal allergens leads to morphologic changes and cytokine production," Journal of Allergy and Clinical Immunology, vol. 105, no. 6, pp. 1185-1193, 2000.

[99] P. Borger, G. H. Koëter, J. A. B. Timmerman, E. Vellenga, J. F. C. Tomee, and H. F. Kauffman, "Proteases from Aspergillus fumigatus induce interleukin (IL)-6 and IL-8 production in airway epithelial cell lines by transcriptional mechanisms," Journal of Infectious Diseases, vol. 180, no. 4, pp. 1267-1274, 1999.

[100] L. L. Chiu, D. W. Perng, C. H. Yu, S. N. Su, and L. P. Chow, "Mold allergen, Pen c 13, induces IL-8 expression in human airway epithelial cells by activating protease-activated receptor 1 and 2," Journal of Immunology, vol. 178, no. 8, pp. 5237-5244, 2007.

[101] K. Page, J. R. Ledford, P. Zhou, K. Dienger, and M. WillsKarp, "Mucosal sensitization to German cockroach involves protease-activated receptor-2," Respiratory Research, vol. 11, p. 62,2010

[102] N. G. Arizmendi, M. Abel, K. Mihara et al., "Mucosal allergic sensitization to cockroach allergens is dependent on proteinase activity and proteinase-activated receptor-2 activation," Journal of Immunology, vol. 186, no. 5, pp. 31643172, 2011.

[103] K. Wada, Y. Matsuwaki, H. Moriyama, and H. Kita, "Cockroach induces inflammatory responses through proteasedependent pathways," International Archives of Allergy and Immunology, vol. 155, supplement 1, pp. 135-141, 2011.

[104] K. E. Lee, J. W. Kim, K. Y. Jeong, K. E. Kim, T. S. Yong, and M. H. Sohn, "Regulation of German cockroach extract-induced IL-8 expression in human airway epithelial cells," Clinical and Experimental Allergy, vol. 37, no. 9, pp. 1364-1373, 2007.

[105] M. F. Lee, N. M. Wang, S. W. Liu, S. J. Lin, and Y. H. Chen, "Induction of interleukin 8 by American cockroach allergens from human airway epithelial cells via extracellular signal regulatory kinase and jun $\mathrm{N}$-terminal kinase but not p38 mitogen-activated protein kinase," Annals of Allergy, Asthma and Immunology, vol. 105, no. 3, pp. 234-240, 2010.

[106] J. H. Hong, S. I. Lee, K. E. Kim et al., "German cockroach extract activates protease-activated receptor 2 in human airway epithelial cells," Journal of Allergy and Clinical Immunology, vol. 113, no. 2, pp. 315-319, 2004.

[107] K. Page, V. S. Strunk, and M. B. Hershenson, "Cockroach proteases increase IL-8 expression in human bronchial epithelial cells via activation of protease-activated receptor (PAR)-2 and extracellular-signal-regulated kinase," Journal of Allergy and Clinical Immunology, vol. 112, no. 6, pp. 11121118, 2003.

[108] K. Page, V. S. Hughes, K. K. Odoms, K. E. Dunsmore, and M. B. Hershenson, "German cockroach proteases regulate interleukin-8 expression via nuclear factor for interleukin6 in human bronchial epithelial cells," American Journal of 
Respiratory Cell and Molecular Biology, vol. 32, no. 3, pp. 225231, 2005.

[109] K. Page, V. S. Hughes, G. W. Bennett, and H. R. Wong, "German cockroach proteases regulate matrix metalloproteinase9 in human bronchial epithelial cells," Allergy, vol. 61, no. 8, pp. 988-995, 2006.

[110] C. Ebeling, T. Lam, J. R. Gordon, M. D. Hollenberg, and H. Vliagoftis, "Proteinase-activated receptor-2 promotes allergic sensitization to an inhaled antigen through a TNF-mediated pathway," Journal of Immunology, vol. 179, no. 5, pp. 29102917, 2007.

[111] Y. J. Liu, "Thymic stromal lymphopoietin: master switch for allergic inflammation," Journal of Experimental Medicine, vol. 203, no. 2, pp. 269-273, 2006.

[112] D. F. Gudbjartsson, U. S. Bjornsdottir, E. Halapi et al., "Sequence variants affecting eosinophil numbers associate with asthma and myocardial infarction," Nature Genetics, vol. 41, no. 3, pp. 342-347, 2009.

[113] J.-Q. He, T. S. Hallstrand, D. Knight et al., "A thymic stromal lymphopoietin gene variant is associated with asthma and airway hyperresponsiveness," Journal of Allergy and Clinical Immunology, vol. 124, no. 2, pp. 222-229, 2009.

[114] G. M. Hunninghake, J. Lasky-Su, M. E. Soto-Quirós et al., "Sex-stratified linkage analysis identifies a female-specific locus for IgE to cockroach in Costa Ricans," American Journal of Respiratory and Critical Care Medicine, vol. 177, no. 8, pp. 830-836, 2008.

[115] M. Harada, T. Hirota, A. I. Jodo et al., "Functional analysis of the thymic stromal lymphopoietin variants in human bronchial epithelial cells," American Journal of Respiratory Cell and Molecular Biology, vol. 40, no. 3, pp. 368-374, 2009.

[116] M. Harada, T. Hirota, A. I. Jodo et al., "Thymic stromal lymphopoietin gene promoter polymorphisms are associated with susceptibility to bronchial asthma," American Journal of Respiratory Cell and Molecular Biology, vol. 44, no. 6, pp. 787793, 2011.

[117] B. Zhou, M. R. Comeau, T. De Smedt et al., "Thymic stromal lymphopoietin as a key initiator of allergic airway inflammation in mice," Nature Immunology, vol. 6, no. 10, pp. 1047-1053, 2005.

[118] S. Ying, B. O’Connor, J. Ratoff et al., "Thymic stromal lymphopoietin expression is increased in asthmatic airways and correlates with expression of Th2-attracting chemokines and disease severity," Journal of Immunology, vol. 174, no. 12, pp. 8183-8190, 2005.

[119] S. Ying, B. O'Connor, J. Ratoff et al., "Expression and cellular provenance of thymic stromal lymphopoietin and chemokines in patients with severe asthma and chronic obstructive pulmonary disease," Journal of Immunology, vol. 181, no. 4, pp. 2790-2798, 2008.

[120] P. Angkasekwinai, H. Park, Y. H. Wang et al., "Interleukin 25 promotes the initiation of proallergic type 2 responses," Journal of Experimental Medicine, vol. 204, no. 7, pp. 15091517, 2007.

[121] Y. H. Wang, P. Angkasekwinai, N. Lu et al., "IL-25 augments type 2 immune responses by enhancing the expansion and functions of TSLP-DC-activated Th2 memory cells," Journal of Experimental Medicine, vol. 204, no. 8, pp. 1837-1847, 2007.

[122] C. L. Sokol, G. M. Barton, A. G. Farr, and R. Medzhitov, "A mechanism for the initiationof allergen-induced $\mathrm{T}$ helper type 2 responses," Nature Immunology, vol. 9, no. 3, pp. 310$318,2008$.
[123] H. S. Yu, P. Angkasekwinai, S. H. Chang, Y. Chung, and C. Dong, "Protease allergens induce the expression of IL-25 via Erk and p38 MAPK pathway," Journal of Korean Medical Science, vol. 25, no. 6, pp. 829-834, 2010.

[124] T. Ito, Y. H. Wang, O. Duramad et al., "TSLP-activated dendritic cells induce an inflammatory $\mathrm{T}$ helper type 2 cell response through OX40 ligand," Journal of Experimental Medicine, vol. 202, no. 9, pp. 1213-1223, 2005.

[125] Y. H. Wang, T. Ito, Y. H. Wang et al., "Maintenance and polarization of human $\mathrm{TH} 2$ central memory $\mathrm{T}$ cells by thymic stromal lymphopoietin-activated dendritic cells," Immunity, vol. 24, no. 6, pp. 827-838, 2006.

[126] H. Kouzaki, S. M. O'Grady, C. B. Lawrence, and H. Kita, "Proteases induce production of thymic stromal lymphopoietin by airway epithelial cells through protease-activated receptor-2," Journal of Immunology, vol. 183, no. 2, pp. 14271434, 2009.

[127] Y. Kikuchi, T. Takai, T. Kuhara et al., "Crucial commitment of proteolytic activity of a purified recombinant major house dust mite allergen der 1 to sensitization toward IgE and IgG responses," Journal of Immunology, vol. 177, no. 3, pp. 16091617, 2006.

[128] L. Gough, O. Schulz, H. F. Sewell, and F. Shakib, "The cysteine protease activity of the major dust mite allergen der $\mathrm{p} 1$ selectively enhances the immunoglobulin E antibody response," Journal of Experimental Medicine, vol. 190, no. 12, pp. 1897-1901, 1999.

[129] L. Gough, E. Campbell, D. Bayley, G. Van Heeke, and F. Shakib, "Proteolytic activity of the house dust mite allergen Der p 1 enhances allergenicity in a mouse inhalation model," Clinical and Experimental Allergy, vol. 33, no. 8, pp. 11591163, 2003.

[130] L. Gough, H. F. Sewell, and F. Shakib, "The proteolytic activity of the major dust mite allergen Der $\mathrm{p} 1$ enhances the IgE antibody response to a bystander antigen," Clinical and Experimental Allergy, vol. 31, no. 10, pp. 1594-1598, 2001.

[131] R. Fattouh, M. A. Pouladi, D. Alvarez et al., "House dust mite facilitates ovalbumin-specific allergic sensitization and airway inflammation," American Journal of Respiratory and Critical Care Medicine, vol. 172, no. 3, pp. 314-321, 2005.

[132] V. P. Kurup, J. Q. Xia, H. D. Shen et al., "Alkaline serine proteinase from Aspergillus fumigatus has synergistic effects on Asp-f-2-induced immune response in mice," International Archives of Allergy and Immunology, vol. 129, no. 2, pp. 129137, 2002.

[133] C. R. A. Hewitt, A. P. Brown, B. J. Hart, and D. I. Pritchard, "A major house dust mite allergen disrupts the immunoglobulin E network by selectively cleaving CD23: innate protection by antiproteases," Journal of Experimental Medicine, vol. 182, no. 5, pp. 1537-1544, 1995.

[134] O. Schulz, H. F. Sewell, and F. Shakib, "Proteolytic cleavage of $\mathrm{CD} 25$, the $\alpha$ subunit of the human T cell interleukin 2 receptor, by Der $\mathrm{p} 1$, a major mite allergen with cysteine protease activity," Journal of Experimental Medicine, vol. 187, no. 2, pp. 271-275, 1998.

[135] F. Shakib, O. Schulz, and H. Sewell, "A mite subversive: cleavage of CD23 and CD25 by Der p 1 enhances allergenicity," Immunology Today, vol. 19, no. 7, pp. 313-316, 1998.

[136] R. Furmonaviciene, A. M. Ghaemmaghami, S. E. Boyd et al., "The protease allergen Der p 1 cleaves cell surface DC-SIGN and DC-SIGNR: experimental analysis of in silico substrate identification and implications in allergic responses," Clinical and Experimental Allergy, vol. 37, no. 2, pp. 231-242, 2007. 
[137] A. M. Ghaemmaghami, L. Gough, H. F. Sewell, and F. Shakib, "The proteolytic activity of the major dust mite allergen Der p 1 conditions dendritic cells to produce less interleukin-12: allergen-induced Th2 bias determined at the dendritic cell level," Clinical and Experimental Allergy, vol. 32, no. 10, pp. 1468-1475, 2002.

[138] F. Kheradmand, A. Kiss, J. Xu, S. H. Lee, P. E. Kolattukudy, and D. B. Corry, "A protease-activated pathway underlying Th cell type 2 activation and allergic lung disease," Journal of Immunology, vol. 169, no. 10, pp. 5904-5911, 2002.

[139] F. Shakib, A. M. Ghaemmaghami, and H. F. Sewell, "The molecular basis of allergenicity," Trends in Immunology, vol. 29, no. 12, pp. 633-642, 2008.

[140] S. N. Georas, F. Rezaee, L. Lerner, and L. Beck, "Dangerous allergens: why some allergens are bad actors," Current Allergy and Asthma Reports, vol. 10, no. 2, pp. 92-98, 2010. 


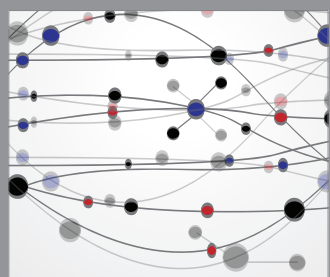

The Scientific World Journal
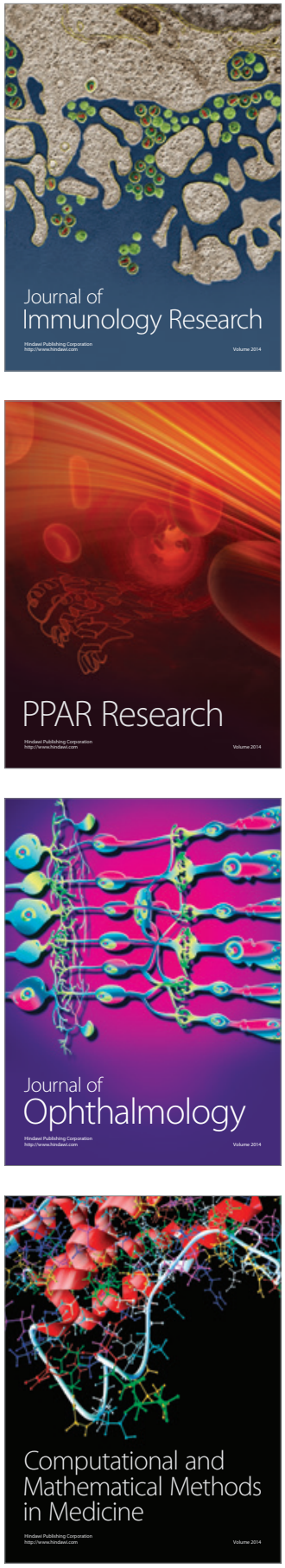

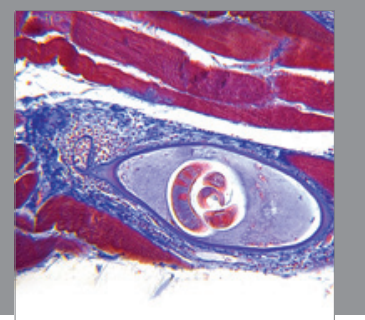

Gastroenterology

Research and Practice
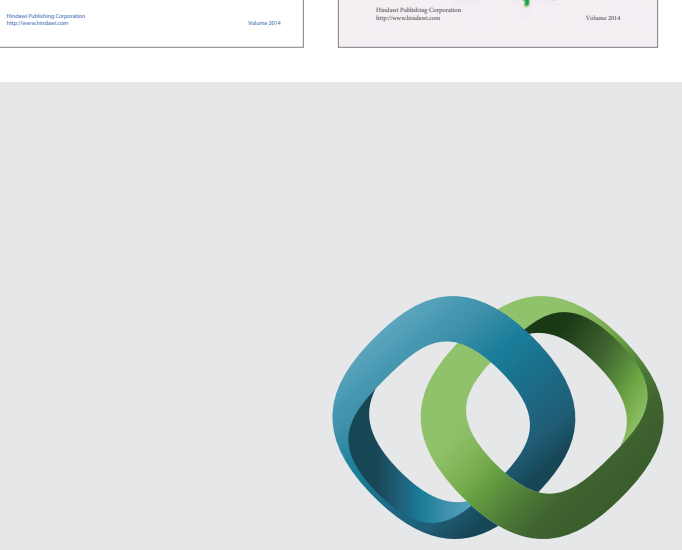

\section{Hindawi}

Submit your manuscripts at

http://www.hindawi.com
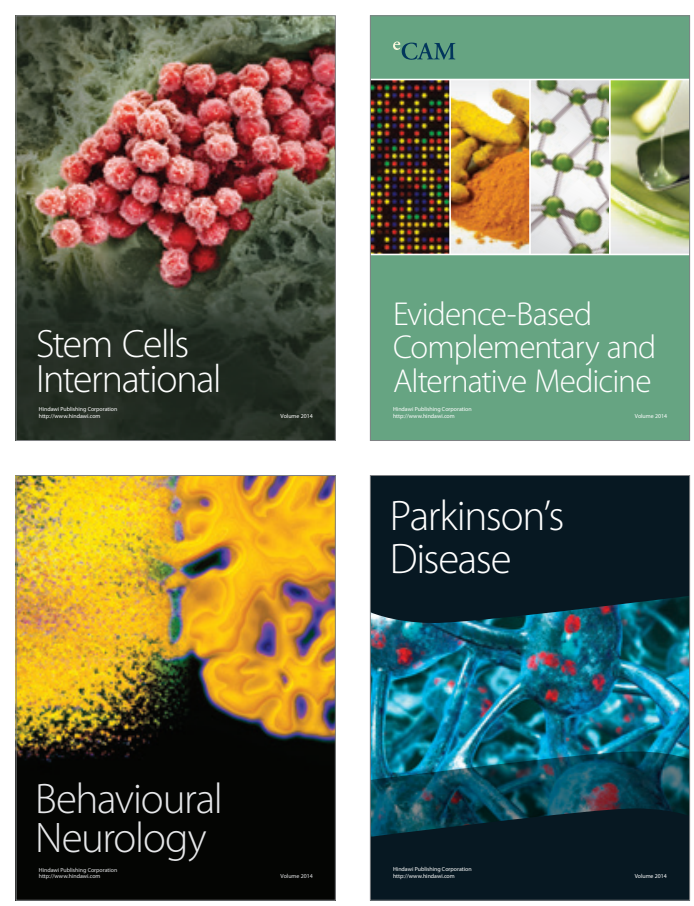

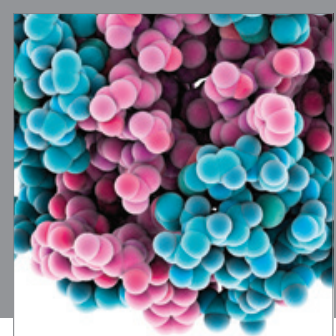

Journal of
Diabetes Research

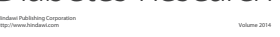

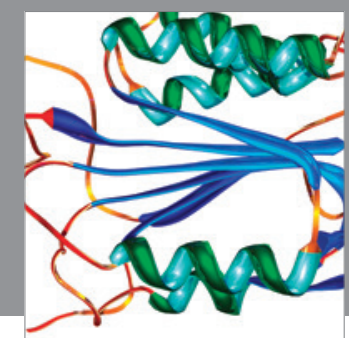

Disease Markers
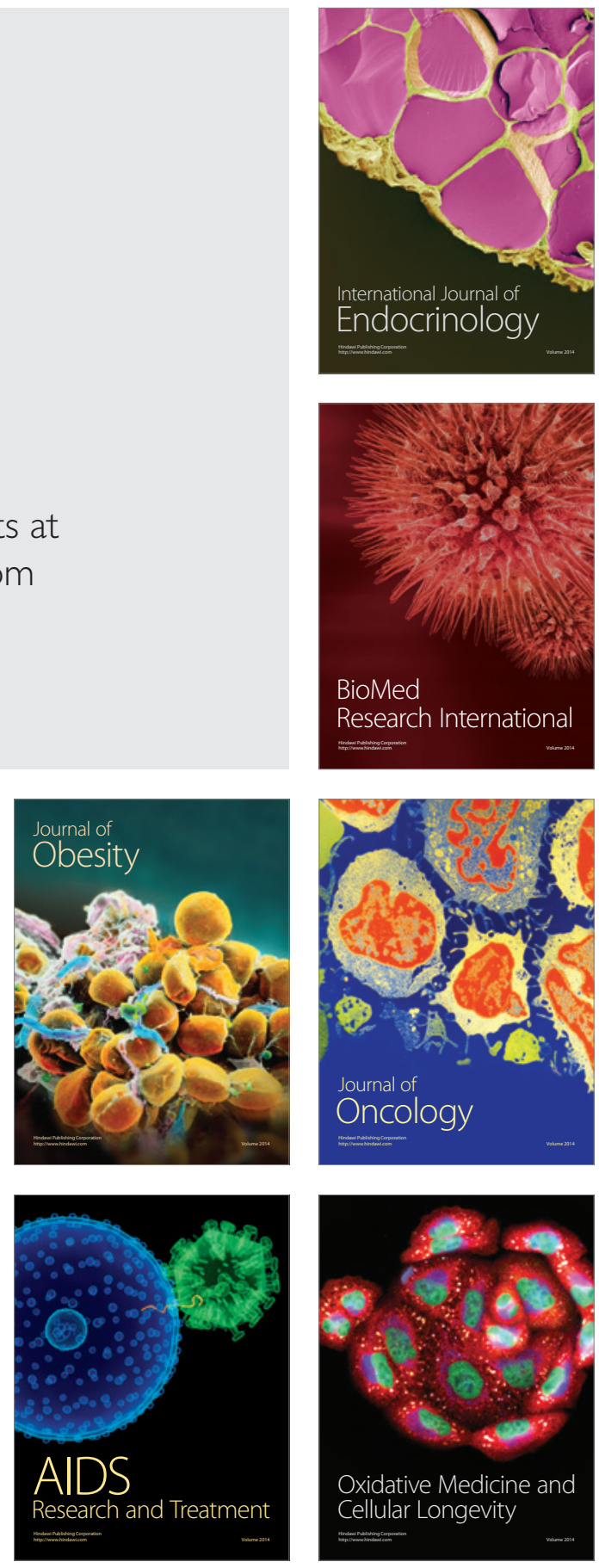